\title{
Median nerve reconstruction after entrapment in the elbow
}

\author{
Lisa Korus MD ${ }^{1}$, Mike Morhart MSc MD FRCSC ${ }^{1}$, Abdulaziz Jarman MD FRCSC ${ }^{1}$, Jaret Olson MD FRCSC ${ }^{1,2}$
}

L Korus, M Morhart, A Jarman, J Olson. Median nerve reconstruction after entrapment in the elbow. Can J Plast Surg 2009;17(4):130-132.

\begin{abstract}
Median nerve entrapment in the elbow is a known but rare complication of pediatric elbow dislocations. It is classified on the anatomical basis of entrapment. Due to a variety of factors, it is often diagnosed late. Because of this, substantial injury occurs to the nerve, requiring some form of restorative surgery in addition to release from the joint. Such nerve injury has been treated in a variety of ways including neurolysis, end-to-end anastomosis and nerve grafting. To date, there has been no conclusive evidence in the literature that one method should be preferred over another. A case of median nerve entrapment that was treated with sural nerve grafting is presented. In a review of the literature, previous treatment of such cases is discussed and compared.
\end{abstract}

Key Words: Elbow; Entrapment; Median nerve; Nerve grafting; Sural nerve ntrapment of the median nerve in the elbow is a rare yet Esevere complication of elbow dislocation and reduction. Primarily a problem that occurs in children, its incidence is approximately $3 \%$ of all elbow dislocations (1). Four types of entrapment have been described: types I to III by Hallet (2) and type IV by al-Qattan et al (3). Type I consists of the median nerve slipping posteriorly behind a torn medial collateral ligament and adhering to the posterior surface of the humerus. Type II is defined when a median nerve becomes entrapped by healed bone after running through a fractured epicondyle. In type III, the nerve becomes entrapped in the humeroulnar joint (2). Type IV is a combination of types I and II (3). Despite the different methods of entrapment there is one common end point: compression leading to ischemia of the nerve. Chronic compression and ischemia in neural tissue can lead to intraneural fibrosis and eventual Wallerian degeneration (4). In addition, median nerve entrapment is often diagnosed late (three months to 2.5 years postinjury), which contributes to the extent of median nerve injury (5). The late diagnosis is not uncommon because the presence of a transient neuropraxia created by contusions or stretching at the time of injury can mimic the signs of an early entrapment (5). Furthermore, children often have difficulty vocalizing their symptoms, making any deficit less apparent (5). Diagnosis has generally consisted of recognizing any nonresolving deficits over time and surgical exploration of the elbow. Radiological changes described by Matev (6) can often be found in cases presenting late due to chronic force applied to the cortex of the bone. Treatment of median nerve entrapment has ranged from simple release and neurolysis to excision and end-to-end anastomosis or nerve grafting.

\section{Reconstruction du nerf médian après pincement dans le coude}

Le pincement du nerf médian au niveau du coude est une complication connue mais rare des dislocations du coude chez l'enfant. On le classe selon le site anatomique du pincement. En raison de divers facteurs, le diagnostic est souvent tardif. C'est pourquoi une atteinte substantielle du nerf s'observe et nécessite parfois une forme de chirurgie corrective, en plus du dégagement de l'articulation. Ce type d'atteinte nerveuse a été traité de diverses façons, y compris par neurolyse, anastomose termino-terminale et greffe nerveuse. À ce jour, aucune preuve concluante dans la littérature n'a permis de privilégier une méthode plutôt qu'une autre. On présente ici un cas de pincement du nerf médian qui a été traité par greffe du nerf sural. Dans une revue de la littérature on aborde et on compare les traitements antérieurs de tels cas.

\section{CASE PRESENTATION}

The case of a seven-year-old girl who had type III entrapment of the median nerve following reduction of an elbow that was dislocated while jumping on a trampoline in June 2003 is presented. Immediately after a painful reduction of the right elbow, numbness was noted in the first and second digits of the right hand. In follow up with an orthopedic surgeon over the next year, anterior interosseous nerve paralysis was noted. A flexion contracture of $20^{\circ}$ had also developed. Almost one year after the initial insult, due to lack of progression in recovery, she was referred to the plastic surgery department at the University of Alberta (Edmonton, Alberta). Examination at this time was suggestive of a full median nerve injury because there was no ability to use her flexor digitorum superficialis in digits 2 to 5 , no flexor digitorum profundus to the index finger and no flexor pollicis longus function. Numbness of the index finger and thumb was noted. There was wasting of the thenar mass, flexor carpi radialis, palmaris longus and abductor pollicis brevis. Electromyography studies confirmed a right median neuropathy. Due to the lapse of 10 months since the initial insult, no further recovery was expected; thus, the decision for exploratory surgery and possible nerve grafting of the right median nerve and anterior interosseous nerve was made.

The patient was sedated under general anesthetic and a tourniquet was applied to the right upper arm. After dissection past the lacertus fibrosus, the median nerve was located ulnar to the brachial artery. As it was followed proximally, the nerve was noted to be thinned and was eventually found to be encased within the elbow joint (Figure 1). The proximal portion the median nerve was then located. It was displaced quite

${ }^{1}$ Plastic and Reconstructive and Pediatric Surgery; ${ }^{2}$ Department of Surgery, University of Alberta Hospital, Edmonton, Alberta

Correspondence: Dr Jaret Olson, 2D3.82 WC Mackenzie Health Sciences Centre, 8440-112 Street, University of Alberta Hospital, Edmonton,

Alberta T6G 2B7. Telephone 780-407-8108, fax 780-407-8131, e-mail jaret.olson@albertahealthservices.ca 


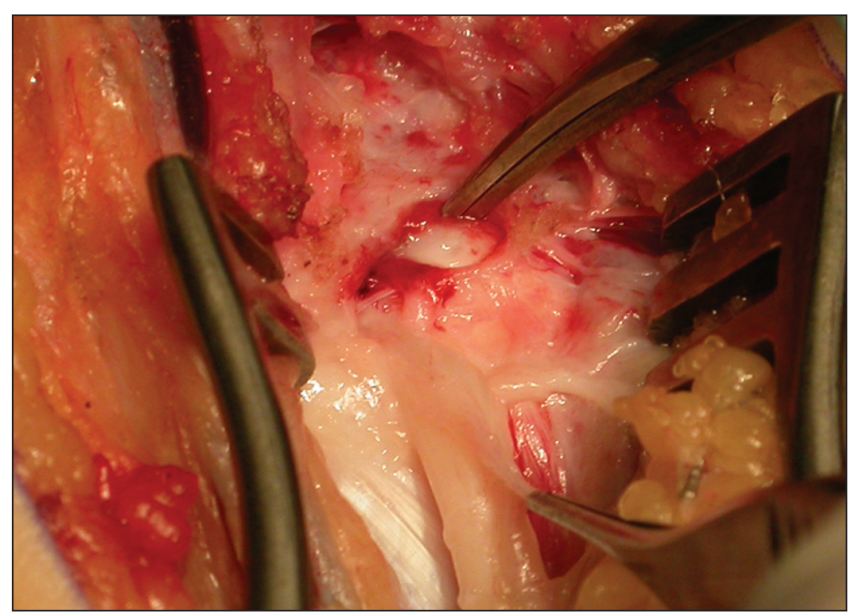

Figure 1) Median nerve entrapped in elbow

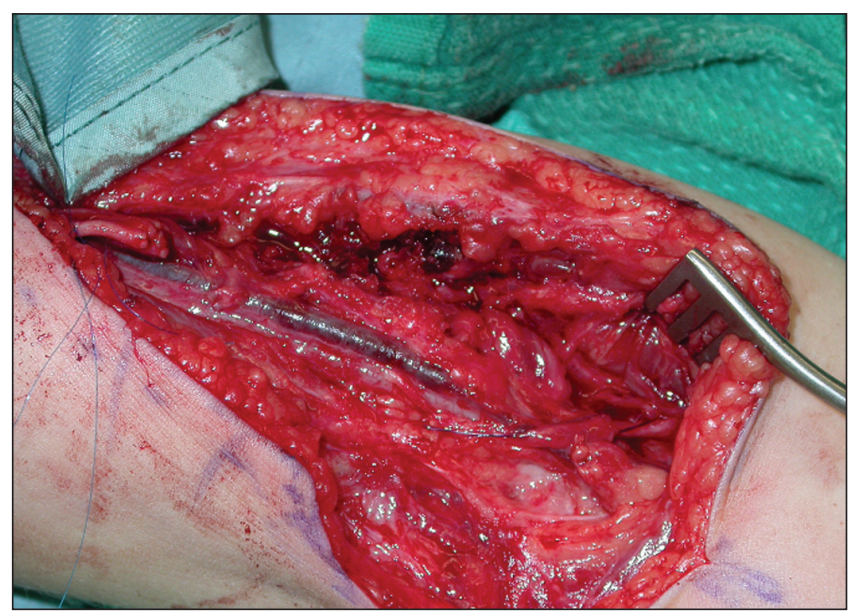

Figure 2) Dissection out of median nerve

ulnarly and was at first thought to be the ulnar nerve; however, the intermuscular septum was pierced and the ulnar nerve was identified. Stimulation of the median nerve elicited no response. The entrapped segment of nerve, which included the anterior interosseous nerve, was then dissected out (Figure 2) and sural nerve was harvested to be used as graft. Three sural nerve grafts were placed in retrograde fashion from the median nerve proper to the distal median nerve, and two sural nerve grafts were used to reconstruct the anterior interosseous nerve. Grafts were secured in place with Tisseel (Baxter International Inc, USA) (Figure 3).

Follow-up at three months postsurgery showed a travelling Tinel's sign approximately $4 \mathrm{~cm}$ below the elbow, demonstrating nerve regeneration.

\section{DISCUSSION}

There have only been three previous reports of sural nerve grafting in median nerve reconstruction after entrapment in the elbow $(3,5,7)$. More often, end-to-end anastomosis is chosen to reconstruct the median nerve (8-12). While this has the advantage of no donor site morbidity and fewer coaptation sites, grafting has the distinct advantage of decreasing tension at the repair site. A review of literature since the first median nerve entrapment case involving resection shows losses of up to $5.5 \mathrm{~cm}$ of nerve, with the mean of reported losses being

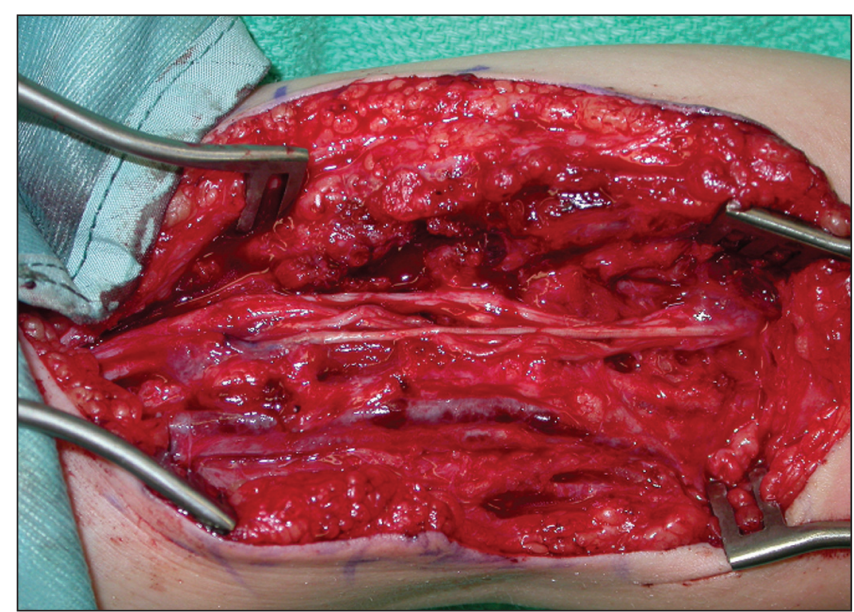

Figure 3) Grafted repair of median nerve

TABLE 1

Sizes of median nerve segment resections as reported in the literature

\begin{tabular}{llcc}
\hline Year & Reference & Type of repair & Length of resection, cm \\
\hline 2003 & Ozkoc et al (8) & $\mathrm{R}$ & 3.0 \\
1995 & Noonan and Blair (5) & $\mathrm{G}$ & 5.5 \\
1994 & al-Quattan et al (3) & $\mathrm{G}$ & 5.0 \\
1986 & Webb and Lourie (9) & $\mathrm{R}$ & Unknown \\
1983 & Green (10) & $\mathrm{R}$ & 4.5 \\
1983 & Ayala et al (7) & $\mathrm{G}$ & 5.0 \\
& & $\mathrm{R}$ & 3.0 \\
1976 & Matev (6) & $\mathrm{R}$ & 3.0 \\
& & $\mathrm{R}$ & 3.5 \\
1974 & Rana et al (11) & $\mathrm{R}$ & 2.0 \\
1973 & Pritchard et al (12) & $\mathrm{R}$ & 4.0 \\
\hline
\end{tabular}

$G$ Sural nerve graft; $R$ Reanastomosis

$3.9 \mathrm{~cm}$ (Table 1). Previous cases have tried reducing the tension on end-to-end anastomosis through splinting the elbow in flexion $(8,10,11)$; however, prolonged immobilization in this position can lead to stiffness and decreased range of motion. Even after coaptation sites have healed, releasing the elbow from a position of flexion can place the shortened nerve under tension causing a decrease in microvascular flow which can affect function. Such factors make primary repair unfavourable if 'postural manipulation' is required (13).

Regardless of technique used, the obstacle of time still remains a problem, because quicker intervention is associated with more favourable outcomes (14). Muscle itself can become irreversibly damaged at 18 months postinjury, therefore reinforcing the benefits of early intervention (15). Median nerve injury is associated with a favourable motor outcome in comparison with ulnar nerve injury (14). In addition, being younger than 16 years of age at time of injury is also associated with favourable outcomes (14). Taking these factors into account, a cautious $50 \%$ to $60 \%$ of motor recovery was anticipated in our case. Given the previous injury to the fingertip, it was hoped that restoration of sensory function would be able to pre-empt future injuries to her hand.

Prompt diagnosis will reduce morbidity in these cases. Total return of function is rarely expected after nerve entrapment, 
highlighting the importance of avoiding nerve entrapment in the first place. Placing a gentle traction on the forearm while it is in flexed position during reduction can be preventive because hyperextension is speculated to predispose the median nerve to intra-articular entrapment (1). If entrapment does occur, early diagnosis can lead to restoration using less invasive measures. Both simple nerve release and neurolysis have demonstrated positive results when the entrapment is caught early and the nerve is not extensively damaged (16-23). Suspicion of nerve entrapment should be raised in cases with difficult reductions, the emergence of median nerve symptoms, more severe pain than usual and an increase in medial joint space on $\mathrm{x}$-ray (2).

Magnetic resonance imaging is a powerful tool to aid in diagnosis preoperatively. Magnetic resonance imaging shows the course of the median nerve and can also serve as an adjunct to electromyography in evaluation of muscle deinnervation through assessment of muscle atrophy (24).

In the event that primary repair or nerve grafting does not yield optimal results, the advent of nerve transfer provides another possible alternative. Use of the flexor carpi ulnaris fascicle of the ulnar nerve can restore thumb opposition, finger flexion and the hand intrinsics (13). Both the ulnar sensory nerve and the dorsal sensory nerve of the radial nerve can be used to return sensation to the key pinch area (13).

Despite the severity of entrapment of the median nerve, its low incidence in elbow reductions does not warrant routine exploration or imaging unless there is high clinical suspicion. The range of time to diagnosis as well as numerous ways the nerve can be entrapped warrant that the approach for restoration of function be tailored to each individual case. Both endto-end anastomosis and sural nerve grafts have been used in cases where median nerve is not viable. There is no clear evidence that one method should be preferred over the other; however, there are distinct advantages to performing a nerve graft such as decreased tension across the repair site and earlier mobilization of the joint, especially when there is the need for extensive resection of the median nerve.

\section{REFERENCES}

1. Ogden JA. Skeletal Injury in the Child. Berlin: Springer-Verlag, 2000:550-1.

2. Hallett J. Entrapment of the median nerve after dislocation of the elbow. J Bone Joint Surg 1981;63B:408-12.

3. al-Qattan MM, Zuker RM, Weinberg MJ. Type 4 median nerve entrapment after elbow dislocation. J Hand Surg [Br] 1994;19:613-5.
4. Mackinnon SE, Lee Dellon A. Surgery of the Peripheral Nerve. New York: Thieme Medical Publishers, 1988.

5. Noonan KJ, Blair WF. Chronic median-nerve entrapment after posterior fracture-dislocation of the elbow. J Bone Joint Surg 1995;77A:1572-5.

6. Matev I. A radiological sign of entrapment of the median nerve in the elbow joint after posterior dislocation. J Bone Joint Surg 1976;58B:353-5.

7. Ayala H, De Pablos J, Gonzalez J, Martinez A. Entrapment of the median nerve after posterior dislocation of the elbow. Microsurgery 1983;4:215-20.

8. Ozkoc G, Akpinar S, Hersekli MA, Ozalay M, Uysal M, Tandogan NR. Type 4 median nerve entrapment in a child after elbow dislocation. Arch Orthop Trauma Surg 2003;123:555-7.

9. Webb S, Lourie J. Median nerve entrapment in an unreduced fracture-dislocation of the elbow: Case report. P N G Med J 1986;29:185-7.

10. Green NE. Entrapment of the median nerve following elbow dislocation. J Pediatr Orthop 1983;3:384-6.

11. Rana NA, Kenwright J, Taylor RG, Rushworth G. Complete lesion of the median nerve associated with dislocation of the elbow joint. Acta Orthop Scand 1974;45:365-9.

12. Pritchard DJ, Linscheid RL, Svien HJ. Intra-articular median nerve entrapment with dislocation of the elbow. Clin Orthop Relat Res 1973;90:100-3.

13. Weber RV, MacKinnon SE. Bridging the neural gap. Clin Plastic Surg 2005;32:605-16.

14. Ruijs AC, Jaquet JB, Kalmijn S, Giele H, Hovius SER. Median and ulnar nerve injuries: A meta-analysis of predictors of motor and sensory recovery after modern microsurgical nerve repair. Plast Reconstr Surg 2005;116:484-94.

15. Ehni BL. Treatment of traumatic peripheral nerve injury. Am Fam Physician 1991;43:897-905.

16. Rao SB, Crawford AH. Median nerve entrapment after dislocation of the elbow in children. A report of 2 cases and review of the literature. Clin Orthop Relat Res 1995;312:232-7.

17. Thorleifsson R, Karlsson J, Thorsteinsson T. Median nerve entrapment in bone after supercondylar fracture of the humerus. Case report. Arch Orthop Trauma Surg 1988;107:183-5.

18. Floyd WE 3rd, Gebhardt MC, Emans JB. Intra-articular entrapment of the median nerve after elbow dislocation in children. J Hand Surg[Am] 1987;12:704-7.

19. Kietsiriroje N, Thepchatri A. Median nerve entrapment after an unusual fracture dislocation of the elbow: A case report. J Med Assoc Thai 1987;70:234-7.

20. Danielsson LG. Median nerve entrapment in the elbow dislocation. A case report. Acta Orthop Scand 1986;57:450-2.

21. Pritchett JW. Entrapment of the median nerve after dislocation of the elbow. J Pediatr Orthop 1984;4:752-3.

22. St Clair Strange FG. Entrapment of the median nerve after dislocation of the elbow. J Bone Joint Surg 1982;64B:224-5.

23. Mannerfelt L. Median nerve entrapment after dislocation of the elbow. J Bone Joint Surg 1968;50B:152-5.

24. Akansel G, Dalbayrak S, Yilmaz M, Bekler H, Arslan A. MRI demonstration of intra-articular median nerve entrapment after elbow dislocation. Skeletal Radiol 2003;32:537-41. 